\title{
Sustainable Development at the Frames of the Strategy “Europe 2020"
}

\author{
Athanasios Anastasiou*, Pasiopoulou Marietta \\ Department of Economics, University of Peloponnese, Peloponnese, Greece \\ Email:*athanastas@uop.gr,marietta.0@hotmail.com
}

How to cite this paper: Anastasiou, A. and Marietta, P. (2020) Sustainable Development at the Frames of the Strategy "Europe 2020". Theoretical Economics Letters, 10, 443-457. https://doi.org/10.4236/tel.2020.103028

Received: November 1, 2019

Accepted: May 18, 2020

Published: May 21, 2020

Copyright $\odot 2020$ by author(s) and Scientific Research Publishing Inc. This work is licensed under the Creative Commons Attribution International License (CC BY 4.0).

http://creativecommons.org/licenses/by/4.0/ (c) (i) Open Access

\begin{abstract}
The environmental protection and the sustainable development, the growth that takes place in parallel and equal promotion of the economy, the society and the environment are now identified necessities and important priorities of the international community. The sustainable development in accordance to the Strategy of "Europe 2020" provides the ability to use technological and scientific achievements in such a way as to create alternative political proposals to ensure increased productivity, efficiency, social consistency and of course, the prudent management of natural resources. This research aims to explain the importance of the implementation of the sustainability/sustainable development/growth and how it is linked to EU's development in some areas (economy, environment). It was created a specific thematic index concerning the sustainable development, to ascertain how various macroeconomic variables and variables related to the environmental growth affect it. Based on the index of "Europe 2020", the way was developed by Pasimeni (2011), in order to quantify and measure the progress of the EE28 countries. The analysis of the performance of each country member of the EU, in the frames of this strategy, as far as concerned their economic and environmental conditions, but also, the development of a methodological framework for the measurement of their benefits through the creation of a panel data model regression, are the objects of interest of this paper. The results showed the deviation of the countries of their goals set by 2020 , concluding that institutional factors influence the course of an economy more than macroeconomic factors do.
\end{abstract}

\section{Keywords}

Sustainable Development/Growth, Climate Change, Environment, Europe 2020

\section{Introduction}

In early 2010, after the failure of the Lisbon Strategy, the European Commission 
aiming at improving the competitiveness of European Union, created a new strategy for smart, sustainable and inclusive growth, known as "Europe 2020" (European Commission, Europe 2020, 2010). The "Europe 2020" Strategy was the first step to adopt of a development model that would not simply seek economic stabilization for the European Union. Ecological reality anticipates political reality, finding and bringing to light fundamental truths in relation to the challenges that the European economy faces, as well. In order for Europe to build a sustainable future, they have to predict over the short term horizon and focus on a better quality of life overall.

The "Europe 2020" Strategy, was launched when the growth rate and the European Union's productivity levels were lower than those of other developed countries and in conditions of a rapidly deteriorating economic and social environment. This strategy was designed in relation to a set of goals focused on the priorities of smart, sustainable and inclusive growth. To accelerate progress, the commission established seven flagship initiatives, including specific work programs in areas considered important growth drivers and served as a reference framework for a series of actions at European level, in the single market of the European Union budget for the period 2014-2020 and its foreign policy. The European Commission launched on 3 March 2010, the new development strategy for the decade 2011-2020, the "Europe 2020", due to a changing world, the European Union to become a smart, sustainable and inclusive economy. Europe is in transition. The economic crisis and the structural weaknesses in Europe's economy are more obvious than ever. The EU must take responsibility for the future and this can only happen if EU acts collectively. All the Member States have committed themselves to achieve the strategic objectives which have now been converted into national targets. The annual process of coordinating economic policies, the "European Semester", will significantly help in proper coordination and targeting of the efforts undertaken at national level in order to obtain the desired results for growth.

\section{The "Europe 2020" aims at a growth that it is:}

a) Smart, with more efficient investments in education, research and innovation,

b) Sustainable, thanks to the decisive transition to a low carbon economy dioxide and a more competitive industry and

c) Inclusive, with particular emphasis on job creation and poverty reduction.

These three elements are the priorities of the Strategy "Europe 2020". They are composed of seven separate pillars, flagship initiatives per module, as shown below. Essentially, these indicators were linked to a set of measurable, acceptable and easily monitored, strong indicators for assessing progress towards achieving the targets. For each initiative, however, the European and the National Authorities should coordinate their efforts to achieve better results [1].

This paper focuses on the analysis of the economic and environmental performance of the countries members of the EU within the Strategy of "Europe 
2020 ", by creating the thematic Sustainable Development Index (SDI), according to "Europe 2020" Index (Pasimeni, 2011). The development of a methodological framework for evaluating its advantages by creating a data model regression will provide to us all the necessary details to figure out how the economic growth affects the environmental growth. Note that there had been a selection and comparison to the most important macroeconomic variables and sub-indicators on Sustainable Development within the Strategy "Europe 2020", for all EU members states.

\section{2. “Europe 2020" Index}

Europe has found new levers to boost economic growth and employment. The problems of these sectors are addressed in the context of the seven (7) flagship initiatives/pillars. For each one, the European and National Authorities should coordinate in order to achieve better results. The most important of these are presented in Table 1 by thematic category [2].

\subsection{Smart Growth}

\subsubsection{Innovation}

The aim is to ensure a strong, competitive and diversified value chain in manufacturing, focusing on small and medium-sized enterprises by speeding up the roll-out of high-speed internet access services, ensuring a strong industrial base but also, by promoting excellent educational systems, modern labor markets and the right mix of skills for Europe's future workforce.

\subsubsection{Education}

"Youth on the Move" is the flagship initiative undertaken by the European Union to respond to the challenges that young people face and to help them learn about success in the knowledge economy.

\subsubsection{Digital Society}

The efficient use of digital technologies will enable Europe to address its main problems and provide European citizens with better quality of life.

\subsection{Sustainable Development}

\subsubsection{Climate, Energy and Mobility}

The effective use of resources, tackling climate change and achieving the goal we have set, to reduce by 2050 greenhouse gas emissions by $80 \%-95 \%$.

Table 1. Priorities of "Europe 2020" Strategy by themes.

\begin{tabular}{ccc}
\hline Smart Growth & Sustainble Growth & Inclusive Growth \\
\hline Innovation & Climate, Energy and Mobility & Empoyment and Skills \\
Education & Comptetitiveness & Fight against Poverty \\
Digital Society & & \\
\hline
\end{tabular}

Source: authors' editing, 2016. 


\subsubsection{Competitiveness}

Increased productivity in manufacturing industry and associated services in order to support the recovery of growth and employment, to restore health and sustainability of the EU economy.

\subsection{Inclusive Development}

\subsubsection{Employment and Skills}

The target is that the employment rate for women and men in the $20-64$ age group should reach $75 \%$ by 2020 , in order to strengthen the sustainability of Europe's social model, social welfare systems, economic growth and public finances.

\subsubsection{Fight against Poverty}

The European Union should bring at least 20 million people out of poverty and social exclusion over the next decade. There is a dynamic framework for action to ensure social and territorial cohesion [3].

The "Europe 2020" Index, developed by Paolo Pasimeni (2011), was based on three thematic indicators reflecting the main pillars of the Strategy, which are in turn made up of sub-indicators, as proposed by the European Commission. All these, help in the study of each thematic Index. These are:

\subsection{Smart Growth Index (SGI)}

\section{Sustainable Development/Growth Index (SDI) and Inclusive Growth Index (IGI)}

The sub-indicators that are associated with them, concern the Percentage of the young Graduates (PYG), the Gross Domestic Expenditure on Research and Development (GDRND), the Greenhouse Gas Emissions (GGE), the Share of the Renewable Energy Sources in gross final consumption (SRES), the Energy Intensity of the Economy (EIE), the Employment Rate of the Population aged 20 - 64 (ERP), the Percentage of Early Leavers the Education (ELE) and the Population who is at Risk of Poverty or Exclusion (PRPE). At Table 2, are shown the indicators and the sub-indicators of those that compose the "EUROPE 2020" Index, and the targets that have to be achieved till 2020, as well. In the Table below (Table 2), the three indicators composing the "Europe 2020" Index and their sub-indices are presented. The objectives to be achieved in each category by 2020 are also outlined below [4].

However, as it is shown in Figure 1, the data express the deviation of many countries concerning the goals. Nordic Europe countries show encouraging growth and they are close enough to each of the 7 pillars goals, with Finland being the best performer. On the other hand, South-East Europe countries show low growth rates in each category and a direct implementation of new policies and reforms are needed. To achieve this new strategic plan, therefore, the EU needs to utilize effectively all the available policies and instruments. Essentially, the EU must acquire regional dimension by the existence of territorial specificities 
Table 2. Indicators and sub-indicators comprising the "Europe 2020" Index and their targets.

\begin{tabular}{c}
\hline Smart Growth Index \\
\hline PYG $(40 \%$ of young graduates should have a degree $)$ \\
GDRND ( $3 \%$ of GDP $)$ \\
\hline Sustainble Development Index \\
\hline GGE $(\downarrow 20 \%$ comparing to 1990 levels $)$ \\
SRES ( $\uparrow$ 20\% $)$ \\
EIE $(20 \%$ of energy $)$ \\
Inclusive Growth Index \\
\hline ERP $(75 \%$ of he population, aged $20-64)$ \\
ELE $(<10 \%)$ \\
PRPE $(\downarrow 20$ millions $)$
\end{tabular}

Source: authors' editing, 2016.

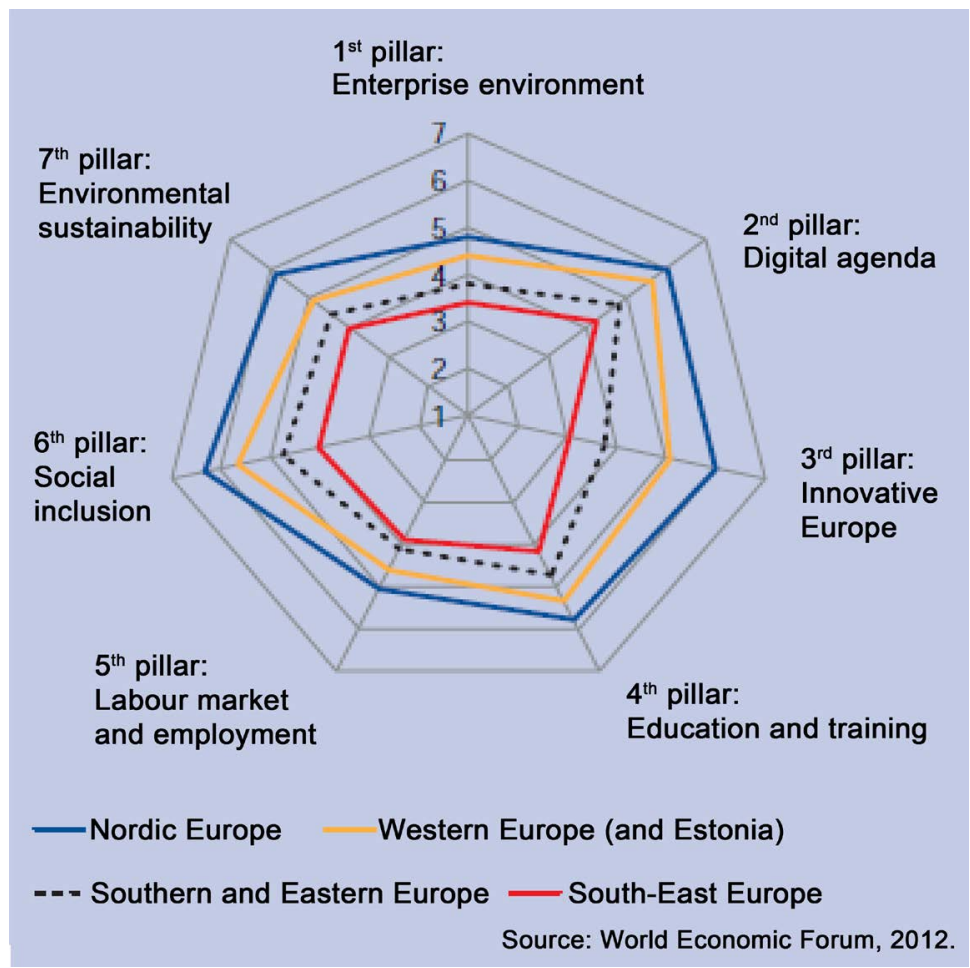

Figure 1. Profile competitiveness four European groups for each pillar of the strategy Europe 2020, (World Economic Forum, 2012).

and assess the territorial impact of policy measures in each country. Furthermore, it is necessary the cooperation of Local and Regional Authorities in achieving the objectives, proper regulation of financial markets and the implementation of appropriate policy actions to ensure transparency. In other words, a regulatory framework is needed. A framework that ensures the effectiveness and the safety of the markets and also, innovative instruments to finance the 
needful investments. It is worth noting that the EU wishes to develop strategic relationships with the emerging economies to discuss issues of common interest, such as the eradication of poverty, the promotion of economic growth and the implementation of the goals. Let's do not forget, though, that each goal should be economically feasible, socially acceptable and ecologically sustainable [5].

\section{5. "Europe 2020" and Sustainable Development}

There is a strong need to create economic growth so as to take into account the limits of the planet and the social justice. That was the exact central theme of the Brundtland report on Sustainable Development (WCED, Brundtland Report, 1987). It focuses on the relationship between the human and the natural environment, emphasizing that the actions of the present generation affects the viability of the future generation [6].

As part of a Sustainable Development, the objectives set, known as the "20-20-20", are referring to (Figure 2):

- The $20 \%$ reduction of total annual emissions of Greenhouse Gases compared to 1990 's levels (the emissions related to land use, forestry, international aviation and maritime transport are not included);

- The $20 \%$ increase of the Energy Intensity of the Economy (the consumption of energy and the overall energy performance of an economy);

- The Renewable Energy Sources should be $20 \%$ of energy in primary energy consumption.

These objectives should be associated, in our minds, with a series of further actions related to building a more competitive low-carbon economy that makes efficient, sustainable use of resources, protecting the environment by reducing greenhouse gas emissions and preventing the loss of biodiversity, exploiting Europe's leadership in developing new green technologies and production methods but also the establishment of an effective system of accountability and transparency, as well as the infliction of environmental taxes in order to keep their promises [7]. Furthermore, the installation of efficient and intelligent electricity networks, the improved business environment and the supplement of assistance to the consumers by providing information to make the right choices, can lead to the achievement of sustainability in all its forms and ultimately, no long-term economic enlargement. That is the new agenda set by 2030 [8].

\section{Sustainable Development and Climate Change}

On Climate Conference, held in Paris on December of 2015, highlighted the need for economies with low $\mathrm{CO}_{2}$ emissions and resilient to climate change, so that there is long term growth. The aim was to maintain the global average temperature increase below $2^{\circ} \mathrm{C}$ above the pre-industrial levels by 2020 and limit the use of fossil fuels, stressing the importance of implementation of the commitments of each country. In order to achieve this, it is necessary all the National Governments and the Local Authorities to cooperate and be part of this commitment. 


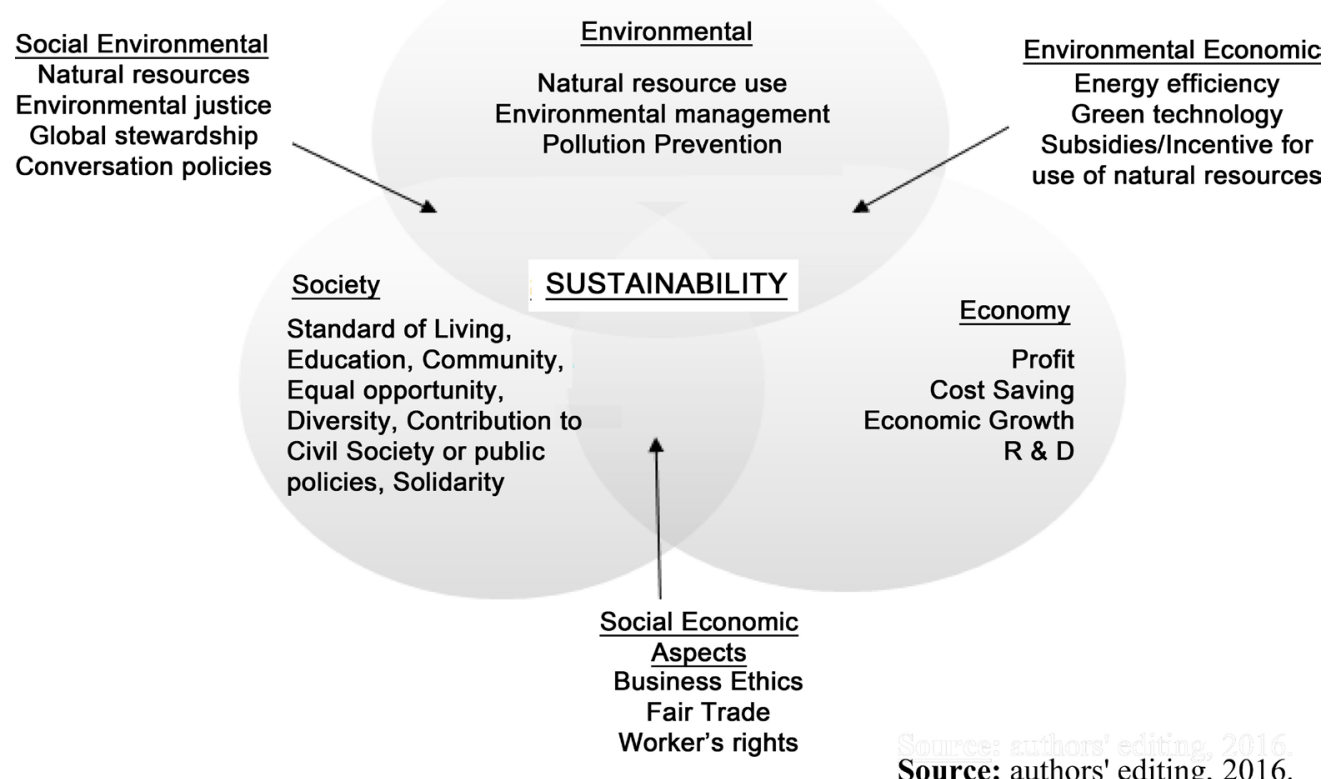

Figure 2. Pillars of sustainable development.

Many countries were interested and it was evident from the participation in the next World Conference of the Parties on Climate Change (COP22) held in Morocco, Marrakech, on November 2016. The delegates from almost 200 countries, sought to finalize all the necessary details of last year's Paris Agreement, to improve the transparency and to strengthen the control mechanisms. Perhaps the most important issue that was under discussion at the Marrakech meeting was the timetable. The setting up a particular map of actions, with a concluding horizon for the implementation of the agreements. Moreover, the countries have agreed to evaluate the progress made in two years and set new goals if necessary. Many developing states, most at risk from the upcoming climate change, pledged to move to an energy model based $100 \%$ on clean energy, particularly wind and solar, by 2050. However, in need of immediate improvement are the evaluation mechanism national strategies, the financing mechanisms for the developing countries and the adaption to the climate change, as well. It is worth mentioning at this point that the richest countries aim to provide $\$ 100$ billion a year in climate finance for the developing countries [9].

\section{Methodology}

For the creation of the thematic Index related to Sustainable Development within the Strategy of "Europe 2020", we consider that each of the three sub-indices represents different aspects of the growth. For this reason, it is explained the fact that they are presented in different units and scales. At first, in order to make a comparison between the sub-indicators, we should normalize of the data so all the prices will be between zero and one just to be comparable. The period which was under consideration, was from 2004 to 2014. 
For the "positive" indicators, the highest figure represents the highest performance (SRES and EIE), we apply the following transformation:

$$
x_{i}^{c}=\frac{x_{i}^{c}-\min _{k} *\left\{x_{i k}\right\}}{\max _{k} *\left\{x_{i k}\right\}-\min _{k} *\left\{x_{i k}\right\}}
$$

where $i$ represents the sub-indicator, $c$ the country, $\min _{\mathrm{k}}$ and $\max _{k}$ are the $\min$ imum and the highest value of the sub-indicator throughout the period and the time available.

For the "negative" indicators, the highest figure represents the minimum performance (GGE), we apply the following transformation:

$$
x_{i}^{c}=\frac{\max _{k} *\left\{x_{i k}\right\}-x_{i}^{e}}{\max _{k} *\left\{x_{i k}\right\}-\min _{k} *\left\{x_{i k}\right\}}
$$

where $i$ represents the sub-indicator, $c$ the country, $\min _{\mathrm{k}}$ and $\max _{k}$ are the $\min$ imum and the highest value of the sub-indicator throughout the period and the time available.

After that and having normalized the data of the sub-indices, we can proceed to the creation of the Sustainable Development Index (SDI) (Graph 1), using the method of Geometric Sum. With this method, we have higher prices on the indices having a greater homogeneity in their components, namely:

$$
I_{g}^{c}=\left(\Pi_{i=1}^{n} x_{i}^{c}\right)^{1 / n} .
$$

\subsection{Panel Data}

Afterwards, we examine the influence of specific factors in a regression model using panel data estimation methods. Specifically, the estimated model is:

$$
Y_{i t}=\beta_{0}+\beta_{1} X 1_{i t}+\beta_{2} X 2_{i t}+\cdots+\beta_{8} X 8_{i t}+U_{i t}
$$

where $Y_{i t}$ is the SDI of the country $i$ at the year $t, X 1_{i t}$ is the rate change of Real Growth of Gross Domestic Product (RGDPGR) of the country $i$ at the year $t, X 2_{i t}$ is the consolidated gross Debt of the general government (DEBT) (\% of GDP) of the country $i$ at the year $t, X 3_{i t}$ is the Deficit/Surplus of the general government (DEBT) (\% of GDP) of the country $i$ at the year $t, X 4_{i t}$ is the Tax Rate on Energy (TAXRATEENERGY), $X 5_{i t}$ is the Revenue from the Environmental Taxes (ENVTAXREV), $X 6_{i t}$ is the Energy Saving (ENSAVING), $X 7_{i t}$ is the Energy Intensity of the Economy (ENINTENSITY) $\kappa a l ~ X 8_{i t}$ is the Dummy variable (DCRISIS) which separates the period of the financial crisis and last but not least, $U_{i t}=\mu_{t}+\varepsilon_{i}+\gamma_{i}, \mu_{t}$ is the constant term that varies over the time and takes into account the fixed eternal influences of the factors that influence the dependent variable and change over time, but not cross-section, $\boldsymbol{\varepsilon}_{i}$ is a random term varying cross section in order to take into account the random layered effects, the factors that affect the dependent variable and vary cross-section but not in time and $\gamma_{i}$ is the not observed variable/heterogeneity ${ }^{1}$ that does not vary over

${ }^{1} \gamma_{i}$. It measures the result of the factors on the country $i$ and are stable over the time. We believe that the coefficient is equal to 1 . 


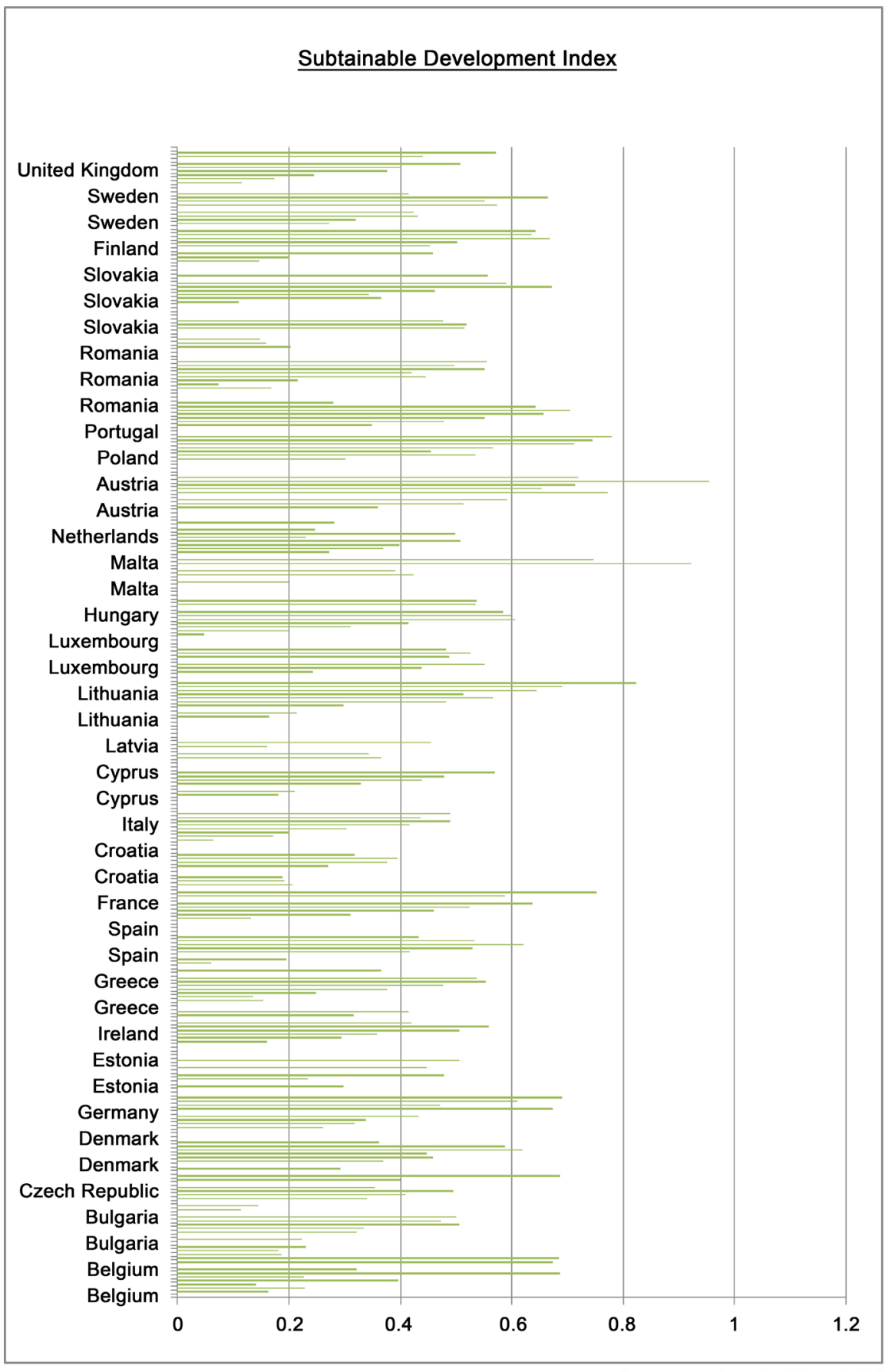

Source: authors' editing, 2016

Graph 1. Sustainable development index, EE28, 2004-2014.

the time for $i=1,2, \ldots N$.

The estimation sample includes annual observations for the EU-28 countries for the period 2004-2014. To estimate the model, the least squares method for panel data was used for layered random effects and fixed effects over time. The panel estimation methods allow the estimation of a model taking into account the existence of heterogeneity in the model, either longitudinal or cross-section. We should check the fixed and random effects of laminar (Fixed and Random 
Effect Model), to examine which is the most appropriate model. The Econometric Program EViews was used in order to make all the checks and run the regressions.

\subsection{Appropriate Model}

Having imported the data into EViews, we perform the regressions, choosing each time combinations of the dependent and the independent variables. To conclude to the most appropriate regression model, however, the one of the fixed effects or random effects, we must perform the Hausman Test, in each regression separately. First, we run each regression with the method of fixed effects and then with that of the random effects, so the Hausman Test will be possible to be performed. Essentially, we check which the most appropriate method is, based on the following assumption:

Ho: I accept the Random Effects as the most appropriate method;

Ha: I accept the Fixed Effects as the most appropriate method.

In order to decide which the most appropriate estimation method of the model is, we have to look at the Prob. value (P-Value) of the test we just made. If the value of Prob. is less than 5\%, that is statistically significant, we reject the null hypothesis (Ho), otherwise we reject the alternative hypothesis (Ha). This assumption is valid for each regression.

Depending on the result, we reject or accept the Ho and then we perform the regression again, having initially set the appropriate method in the panel settings. There, before the completion of the regression, we still need to take into consideration and select the White cross-section, in order to correct the possible existence of residual heteroskedasticity in the model. The results presented in the final table are the values and the estimation of coefficients that define this model.

\section{Data}

The creation of the Composite Sustainable/Green Development/Growth Index is the basic object of the research scope of this investigation. All the necessary statistical information (on annual basis) of the three sub-indices (SRES, EIE, GGE) and the macroeconomic variables for each of the 28 member-states of the European Union (EU-28), for the period from 2004 to 2014, got collected from the database of Eurostat, World Economic Forum and World Bank. We have 308 observations in total. The dependent variable of the model is the Sustainable Development Index. The "Europe 2020" Strategy was officially launched in 2010 and covers the decade 2010-2020. The availability of the data for all variables, however, started earlier, thereby causing, terrible interesting analysis is to monitor the EU-28 before and after the financial crisis situation. The independent variables which were used to see their influence in the dependent, are presented below.

- RGDPGR (Real Growth of Gross Domestic Product, Volume);

- DEBT (Gross Consolidated Debt of general government, \% GDP); 
- DEF_SUR (Deficit and Surplus of general government, \% GDP);

- TAXRATEENERGY(Tax Rate on Energy, EUR per TOE);

- ENVTAXREV (Environmental Tax Revenue, \% GDP);

- ENSAVING (Energy Saving, MTOE);

- ENINTENSITY (Energy Intensity of the economy, gross inland consumption of energy. divide by GDP, kg of oil equivalent per 1000€);

- DCRISIS (Dummy variable associated with the period of the financial crisis. It takes the value 0 for the period 2004-2008 and the value 1 for the period 2009-2014).

\section{Estimation Results}

Table 3 shows the descriptive statistics of the variables that were included in the empirical analysis.

Several regression models were created in order to examine the effect of the independent variables on SDI. Many of these variables have a low correlation with each other, as shown in Table 4.

Table 3. Descriptive Statistics of explanatory variables.

\begin{tabular}{cccccc}
\hline Variable & Mean & Max & Min & St. Dev. & Obs \\
\hline SDI & 0.279 & 0.954 & 0.000 & 0.248 & 308 \\
RGDPGR & 1.764 & 11.900 & -14.800 & 3.932 & 308 \\
DEBT & 56.683 & 180.100 & 3.700 & 32.690 & 308 \\
DEF_SUR & -3.182 & 5.100 & -32.300 & 3.882 & 308 \\
TAXRATEENERGY & 174.914 & 431.650 & 76.440 & 71.296 & 308 \\
ENVTAXREV & 2.623 & 4.990 & 15.700 & 0.621 & 308 \\
ENSAVING & 40.852 & 223.400 & 0.400 & 53.902 & 308 \\
ENINTESITY & 192.886 & 630.600 & 68.600 & 100.536 & 308 \\
DCRISIS & 0.545 & 1.000 & 0.000 & 0.498 & 308 \\
\hline
\end{tabular}

Source: authors' editing, 2016.

Table 4. Correlation of dependent variables.

\begin{tabular}{|c|c|c|c|c|c|c|c|}
\hline & RGDPGR & DEBT & DEF_SUR & $\begin{array}{l}\text { TAXRATE } \\
\text { ENERGY }\end{array}$ & ENVTAXREV & ENSAVING & ENINTESITY \\
\hline RGDPGR & 1.000 & -0.364 & 0.422 & -0.239 & -0.079 & -0.078 & 0.250 \\
\hline DEBT & -0.364 & 1.000 & -0.483 & 0.384 & 0.012 & 0.299 & -0.511 \\
\hline DEF_SUR & 0.422 & -0.483 & 1.000 & 0.025 & 0.163 & -0.047 & 0.140 \\
\hline $\begin{array}{l}\text { TAXRATE } \\
\text { ENERGY }\end{array}$ & -0.239 & 0.384 & 0.025 & 1.000 & 0.540 & 0.313 & -0.663 \\
\hline ENVTAX REV & -0.079 & 0.012 & 0.163 & 0.540 & 1.000 & -0.242 & -0.104 \\
\hline ENSAVING & -0.078 & 0.299 & -0.047 & 0.313 & -0.242 & 1.000 & -0.315 \\
\hline ENINTESITY & 0.2500 & -0.511 & 0.140 & -0.663 & -0.104 & -0.315 & 1.000 \\
\hline
\end{tabular}

Source: authors' editing, 2016. 
At this point, we should mention that before we proceeded to make all the necessary tests and perform the regressions, we made some hypotheses regarding to the residuals.

We assumed that the residuals:

- Have homoskedasticity;

- Follow the normal distribution;

- Show no autocorrelation.

\begin{tabular}{|c|c|c|c|c|c|c|c|c|c|c|c|c|c|c|c|c|}
\hline & & endent Var & riable : Su & Istainable & Developg & ment Index & & & & & & & & & & \\
\hline & _(a) & -(b) & _(c) & - (d) & -(e) & (f) & (g) & (h) & (i) & -(j) & $\ldots(k)$ & -(l) & -(m) & (n) & $\ldots(0)$ & $\ldots$ \\
\hline $\begin{array}{l}\text { Explanatory } \\
\text { Variables }\end{array}$ & & & & & & & & & & & & & & & & \\
\hline Constant & 0.0905 & 0.5489 & 0.3404 & 0.3101 & 0.6575 & 0.7794 & 0.1704 & 0.2123 & -0.0483 & 0.4257 & 0.6184 & 0.8125 & 0.0611 & 0.7040 & 0.3446 & 0.7788 \\
\hline & $(0.4033)$ & $(0.3393)$ & $(0.1254)$ & (0.3593) & $(0.1802)$ & $(0.1546)$ & $(0.0810)$ & $(0.1056)$ & $(0.3764)$ & $(0.3729)$ & $(0.2018)$ & $(0.1162)$ & (0.3944) & $(0.3370)$ & $(0.1233)$ & $(0.1596)$ \\
\hline RGDPGR & 0.0032 & -0.0031 & 0.0048 & -0.0051 & 0.0024 & -0.0049 & 0.0018 & -0.0063 & 0.0029 & -0.0059 & 0.0033 & 0.0026 & - & - & 0.0005 & 0.0049 \\
\hline & $(0.0083)$ & $(0.0056)$ & $(0.0090)$ & $(0.0066)$ & $(0.0092)$ & $(0.0071)$ & $(0.0087)$ & $(0.0082)$ & $(0.0089)$ & $(0.0069)$ & $(0.0089)$ & $(0.0063)$ & & & $(0.0088)$ & $(0.0069)$ \\
\hline DEBT & -0.0018 & 0.0007 & -0.0002 & 0.0005 & -0.0027 & $-3.51 \mathrm{E}-05$ & -0.0001 & 0.0006 & -0.0018 & $0.0021^{*}$ & $-0.0034 *$ & -0.0002 & - & - & & - \\
\hline & $(0.0016)$ & $(0.0012)$ & $(0.0004)$ & $(0.0011)$ & $(0.0016)$ & $(0.0011)$ & $(0.0003)$ & $(0.0014)$ & $(0.0017)$ & $(0.0011)$ & $(0.0018)$ & $(0.0016)$ & & & & \\
\hline DEF_SUR & -0.0054 & $-0.0122 *$ & -0.0011 & -0.010 & -0.0049 & -0.0110 & -0.0024 & $-0.0133^{*}$ & -0.0038 & -0.1037 & -0.0075 & $-0.0142^{* *}$ & 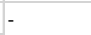 & - & -0.0002 & -0.0110 \\
\hline & $(0.0045)$ & $(0.0064)$ & $(0.0059)$ & $(0.0068)$ & $(0.0053)$ & $(0.0072)$ & $(0.0056)$ & $(0.0072)$ & $(0.0049)$ & $(0.0069)$ & $(0.0052)$ & $(0.0067)$ & & & $(0.0063)$ & $(0.0076)$ \\
\hline TAXRATE & $6.26 \mathrm{E}-05$ & 0.0007 & 0.0001 & $0.0020 * *$ & 8.78E-05 & 0.0015 & 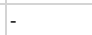 & & & - & - & & -0.0005 & 0.0016 & 0.0001 & 0.0015 \\
\hline ENERGY & $(0.0007)$ & $(0.0009)$ & $(0.0004)$ & $(0.0009)$ & $(0.0010)$ & $(0.0011)$ & & & & & & & $(0.0010)$ & $(0.0011)$ & $(0.0003)$ & $(0.001)$ \\
\hline & -0.0911 & $-0.1770 *$ & $-0.0686 * *$ & & -0.1453 & - & 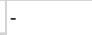 & & -0.1198 & - & - & & -0.0798 & $-0.2397 * *$ & & - \\
\hline ENTAXREV & $(0.0964)$ & $(0.1058)$ & $(0.0286)$ & $(0.1004)$ & $(0.1128)$ & $(0.1056)$ & & & $(0.0817)$ & $(0.0816)$ & & & $(0.1040)$ & $(0.1152)$ & $(0.0270)$ & $(0.1130)$ \\
\hline ENSAVING & $0.0147 * *$ & 0.0102 & 0.0001 & 0.0098 & & - & - & & $0.0144 * *$ & 0.0072 & & 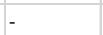 & $0.0156^{* *}$ & 0.0084 & & - \\
\hline & $(0.0064)$ & $(0.0066)$ & $(0.0003)$ & $(0.0067)$ & & & & & $(0.0064)$ & $(0.0067)$ & & & $(0.0066)$ & $(0.0073)$ & & \\
\hline $\begin{array}{l}\text { ENINTEN- } \\
\text { SITY }\end{array}$ & $-0.0011^{*}$ & $-0.0022 * * *$ & & & & - & - & & & (1) & $-0.0015 *$ & $0.0028^{* *}$ & $-0.0012^{*}$ & $0.0022^{* *}$ & & - \\
\hline & $(0.0006)$ & $(0.0004)$ & & & & & & & & & $(0.0008)$ & $(0.0003)$ & $(0.0006)$ & $(0.0005)$ & & \\
\hline DCRISIS & 0.2303 & - & 0.1888 & - & 0.2306 & - & 0.1940 & - & 0.2602 & - & 0.2143 & $x_{2}$ & 0.2112 & - & 0.1854 & - \\
\hline & $(0.1084)$ & & $(0.0764)$ & & (0.1015) & & $(0.0767)$ & & $(0.0952)$ & & $(0.1083)$ & & $(0.0755)$ & & $(0.0738)$ & \\
\hline No of Obs. & 308 & 308 & 308 & 308 & 308 & 308 & 308 & 308 & 308 & 308 & 308 & 308 & 308 & 308 & 308 & 308 \\
\hline R-Square & 0.3160 & 0.247 & 0.1751 & 0.2168 & 0.2846 & 0.2063 & 0.1513 & 0.1480 & 0.3073 & 0.2039 & 0.2827 & 0.2181 & 0.3085 & 0.2149 & 0.1743 & 0.2063 \\
\hline $\begin{array}{l}\text { R-Square } \\
\text { (adj.) }\end{array}$ & 0.2280 & 0.1533 & 0.1559 & 0.1225 & 0.1984 & 0.1139 & 0.1401 & 0.0557 & 0.2238 & 0.1113 & 0.1992 & 0.1303 & 0.2281 & 0.1267 & 0.1606 & 0.1171 \\
\hline $\begin{array}{l}\text { Durbin- } \\
\text { Watson }\end{array}$ & 1.605 & 1.481 & 1.476 & 1.681 & 1.681 & 1.510 & 1.429 & 1.416 & 1.598 & 1.411 & 1.698 & 1.537 & 1.568 & 1.411 & 1.473 & 1.509 \\
\hline
\end{tabular}

Thus, having the values of the estimated coefficients, each regression is modeled on the current price. Specifically, trying to test which model is the most appropriate via the Hausman Test, we found that the Prob. value is 0.0016 which is less than $5 \%$. According to the null hypothesis $(\mathrm{Ho})$ and the alternative hypothesis ( $\mathrm{Ha}$ ) we made above, we can reject the Ho that the Random Effect Model is the most appropriate model and we accept the $\mathrm{Ha}$ where the most appropriate Model is the Fixed Effect Model. So, each model is formulated according to this hypothesis.

\section{Commentary of the Results}

The results from the empirical analysis identify the relationship of the independent variables with the dependent, as presented in Table 4. The effect of the analyzed compared variables is quite significant in all statistical terms. The estimated coefficient of each independent variable (coefficient $b$ ) shows how SDI is affecting by each one of the variables (i.e. when the respective independent variable is changed by one unit, the expected average value of SDI will change in that 
value of estimated coefficient depending on the sign of its price each time).

With regard to the values of Prob. (P-Value) of the independent variables, they demonstrate their statistically significance and they can suitable to explain the SDI, in most regressions, although the degree of suitability of the models (R-square) is not quite satisfying because it does not exceed the $50 \%$ of the data variability. The Prob. value (F-Statistic) of each regression, is statistically significant, making each model appropriate and we can proceed to the interpretation.

The values of the energy intensity of the economy reveal the direct influence of the SDI and the negative impact it has on him. In other words, for each increase of the energy intensity of the economy by one unit, the expected average value of SDI will be reduced by the estimated value in each regression. Something similar applies for the revenue from environmental taxes, whose decrease is quite evident. Small deficit is presented to most models while the values of the debt confuse us a lot. All the variables and especially the Dummy variable concerning the period of the financial crisis, play an important role indicating the strong effect of the financial unbalance in SDI. The tax rate on energy has only positive effects on SDI as energy reserves affect highly positively. It is striking that the real GDP growth rate has no significant relationship with the SDI in any of the regressions, showing how unstable is the economic prosperity of the countries in Europe.

The statistical analysis of the Durbin-Watson's values indicates a possible case where the standard errors might not be independent between each other but that we could say that with certainty, if only the values were less than 1 or greater than 3 (this is not happening in our results). With the values of each regression to tend to 2, we suppose that there is no autocorrelation of the residuals. So, none hypothesis we made above is violated and as a result, the estimated coefficients can explain each regression model.

We should also mention that the Dummy variable was necessary to be included in the models, so that we could have some knowledge to what is going on the state of EU member states countries before the financial crisis and beyond.

\section{Conclusions}

The strong interest on Sustainable Development in recent years has been a great change in the understanding of humanity's relationship with the natural environment. In the last decade, we created all the appropriate conditions for a gradual change of conditions and directions of the development process. Plenty of international conventions and conferences to deal with major environmental issues, have been initiated, while, at the same time, there is a dynamic development of a new scientific field, which aims at the composition of economic and ecological theories, while it is constantly enriched by incorporating new data from modern reality.

The Sustainable Growth, however, is at a fairly large extent, a controversial concept. When referring to this concept, we should focus on the simultaneous 
development of all sectors. In this light, given that the environmental crisis is increasingly deteriorating, it is urgent to establish a more important dialogue, in order to develop and implement new policies, more effective and with greater social consensus. The participation of the society and the non-governmental organizations to the new forms of governance is of course necessary.

It is estimated that the Sustainable Development will constitute the most important challenge for the new balance between the natural environment and the economy. It is an attempt to go beyond a mere finding of natural limits set by the planet, in the economic process and find out how, with what resources and what extent, the socio-economic goals, which are traditionally associated with the development, can keep up with the concern for the quality of the environment and the equality between the generations.

The creation of the Sustainable Development Index within the Strategy "Europe 2020" and its comparison with the most important macroeconomic variables that affect the function of an economy, but also with variables related to the environment, showed the negative impact on Sustainable Growth, consisting of 28 countries members of the EU and covering the period 2004-2014. The weakness of the EU-28 member states to combine the growth of economy, social and environmental, shows clearly the need for structural reforms, redesigning policies and the implementation of measures is considered necessary to correct the various issues that have arisen in the recent years, apart from the appearance of the financial crisis in the European area. All we need are high employment rate, low poverty and high environmental performance. All these should be implemented at regional level and then at transnational, to make progress. It is worth mentioning apart from the macroeconomic factors which were mentioned in this paper, the institutional factors are those that affect directly and drastically the Sustainable Development Index as well as the way of governance of each Member State, including the corruption of the State, and are the factors that give the final touch to its configuration.

\section{References}

[1] European Commission (2010) 2020 Final Statement from the Commission Europe 2020: A Strategy for Smart, Sustainable and Inclusive Growth. http://eur-lex.europa.eu/LexUriServ/LexUriServ

[2] World Economic Forum (2012) The Europe 2020 Competitiveness Report: Building a More Competitive Europe.

[3] Eurostat Publication (2015) Smarter, Greener, More Inclusive? Indicators to Support the Europe 2020 Strategy. http://ec.europa.eu/eurostat/product?code=KS-EZ-14-001

[4] Pasimeni, P. (2012) Measuring Europe 2020: A New Tool to Assess the Strategy. International Journal of Innovation and Regional Development, 4, 365-385. https://doi.org/10.1504/IJIRD.2012.048986

[5] Liargovas, P., Skintzi, V., Daskalopoulou, E., Anastasiou, A., Apostolopoulos, N. and Mitsi, D. (2015) Strategic Plan for Economic and Social Development Europe 
2020: Trends, Prospects and the Situation of Greece. Labor Institute GSEE. http://www.ineobservatory.gr

[6] Brundtland, G., Khalid, M., Agnelli, S., Al-Athel, S., Chidzero, B., Fadika, L., Hauff, V., Lang, I., Ma, S.J., de Botero, M.M., Singh, M., Okita, S., et al. (1987) Our Common Future: Brundtland Report.

[7] Sustainable Growth: Promoting a Greener, Competitive and Efficient in the Use of Economic Resources (2012)

http://www.ec.europa.eu/europe2020/europe-2020-in-a-nutshell/priorities/sustaina ble-growth/index el.htm

[8] Sustainable Development for All: A New Agenda for 2030 (2015) http://ec.europa.eu/enWCEDvironment/news/efe/articles/2015/09/article 20150925 01 en.htm

[9] United Nations Framework Convention on Climate Change, Marrakech. http://unfccc.int/2860.php 